\title{
Der Mechanismus der Darmresorption bei den Octopoden.
}

\author{
Von \\ Otto Cohnheim.
}

(Aus dem physiologischen Laboratorium der zoologischen Station zu Neapel.)

(Der Redaction zugegangen am 12. Mai 1902.)

Bei Gelegenheit der in der vorhergehenden Mittheilung geschilderten Versuche habe ich noch eine andere Beobachtung gemacht, die mir für die Frage der Thätigkeit des Darmepithels bei der Resorption von Interesse zu sein scheint.

Wenn ich bei den Resorptionsversuchen am isolirten, in seinem Blute schwimmenden Darm von Octopus oder Eledone in den Darm eine verdünnte Lösung von Jodnatrium in Seewasser einführte, konnte ich am nächsten Morgen das Jodnatrium im Blute in reichlicher Menge nachweisen, in der im Darmlumen befindlichen Flüssigkeit dagegen nicht mehr. Ich führte den Nachweis, indem ich zu der Lösung Natriumnitrit und Salzsäure setzte und mit Chloroform schüttelte. Dass die Jodreaction im Darminhalt nicht etwa durch das stets vorhandene Eiweiss, durch das meist hinzugefügte Pepton verdeckt wird, wurde erstens durch eine Reihe von Versuchen bewiesen, bei denen der Darm durch ungenügende Lüftung, zu lange Dauer oder ähnliches abstarb; in diesen Fällen konnte ich das Jodnatrium aussen und innen gleichmässig auffinden. Sodann überzeugte ich mich, dass dem Darminhalt zugefügte ganz geringe Spuren von Jodnatrium eine gute Rothfärbung des Chloroforms gaben, und endlich habe ich viele Male den Darminhalt ganz vorsichtig, mit und ohne Sodazusatz verascht und keine Spur von Jodreaction finden können.

Dieses Resultat darf uns nicht überraschen; stellt doch der Thierkörper das Experiment mit Darm und Niere jedesmal an, wenn irgend ein Stoff in der gesammten aufgenommenen Menge resorbirt wird und im Harn wieder erscheint. Immerhin 
ist es uns sonst nicht möglich, die Thätigkeit des resorbirenden Epithels in solcher Reinheit $\mathrm{zu}$ isoliren. Durch osmotische oder Druckkräfte ist ein derartiger restloser Transport von einer Lösung in die andere selbstverständlich unmöglich, er kann nur unter Arbeitsaufwand, d. h. durch Vermittlung der lebenden Zelle geschehen. Dass bei der Dünndarmresorption die lebenden Zellen unentbehrlich sind, steht ja seit Heidenhain fest, und es ist auch, soweit ich sehe, seit den letzten Mittheilungen von Waymouth Reid ${ }^{1}$ ) und mir $^{2}$ ) nicht mehr bestritten worden. Höber ${ }^{3}$ ) gegenüber möchte ich bemerken, dass, wenn er die Resorption des eigenen Serums des Thieres aus dem Dünndarm für einen ganz entscheidenden Beweis hält, er sich viel Mühe hätte sparen können. Denn diese Thatsache ist im Jahre 1869 von Voit und Bauer ${ }^{4}$ ) entdeckt und im Jahre 1894 von Heidenhain ${ }^{5}$ ) in seiner ersten klassischen Resorptionsarbeit von Neuem gefunden und gebührend hervorgehoben worden.

Die Jodresorption bei den Octopoden bildet einen neuen, gut demonstrablen Beweis für die Rolle des Protoplasmas zu den schon bekannten, der Serumresorption und dem activen Flüssigkeitsstrom des isolirten Darmes. Gleichzeitig lehrt sie uns neben der impermeablen Blasenwand, den semipermeablen Blutkörpercher, der Diffusionsmembran des Wirbelthierperitoneums und des Echinodermendarmes und dem Wasser transportirenden Säugethierdarm eine neue Membranart kennen. Denn ich fand am Ende des Versuches die Menge des Darminhaltes gegen den Anfang nicht oder unerheblich vermindert, sodass wir also hier einen Stofftransport ohne gleichzeitigen Wasserstrom haben.

Ausserdem lassen sich die Jodversuche zur Deutung der Organfunction der Octopoden benutzen. Biedermann ${ }^{6}$ ) hat S. 211. 1900.

1) E. Waymouth Reid, Philosoph. Transact. Ser. B, Vol. 192.

2) 0. Gohnheim, Z. f. Biol. 38, 419. 1899. - 39, 169.1899.

3) R. Höber, Pflüger's Arch. 86, 199.1901.

4) C. Voit u. J. Bauer, Z. f. Biologie, 5, 536. 1869.

5) R. Heidenhein, Pflüger's Arch. 56, 579. 1894.

6) W. Biedermann u. P. Moritz, Pflüger's Arch. 75, 1. 1899. 
418 Otto Cohnheim, Der Mechanismus der Darmresorption etc.

gefunden, dass bei den Schnecken die Resorption durch die Leber erfolgt. Für die Cephalopoden war dies schon nach der anatomischen Anordnung unwahrscheinlich, da der Darm bei ihnen nicht der Leber breit anliegt, sondern nur durch 2 enge Gänge mit ihr zusammenhängt. Ich habe denn auch bei den Versuchen, bei denen ich die Leber im Zusammenhange mit dem Darm liess, niemals eine Spur Jod in der Leber, direkt oder nach vorheriger Veraschung, gefunden. Ferner habe ich, wie früher erwähnt, bei einem Theil der Versuche den Kropf entfernt, bei einem andern ihn in Verbindung mit dem Magen gelassen. In den letzteren verschwand das Jodnatrium im Innern des Verdauungskanales nicht, offenbar, weil der selbst nicht resorbirende Kropf, der nur ein Vorrathsraum ist, es immer wieder nachschob. 